\title{
CHAPECÓ: estrutura e dinâmica de uma cidade média no oeste
}

\section{catarinense}

\section{CHAPECÓ: structure and dynamics of an intermediate city in the western region of Santa Catarina}

\author{
Camila Fujita \\ Arquiteta e Urbanista (UFPR), Especialista em Ecoturismo (IBPEx), Mestre em Tecnologia e \\ Desenvolvimento (UTFPR) e Doutora em Arquitetura e Urbanismo (FAU-USP). Professora Adjunto da \\ Pontifícia Universidade Católica do Rio Grande do Sul (PUCRS). \\ camila.fujita@pucrs.br
}

\section{Resumo}

Este artigo apresenta uma análise sobre Chapecó, na região oeste catarinense, tomada a partir da interpretação das transformaç̃oes produtivas, impulsionadas por novos ou tradicionais agentes econômicos, e suas implicações sociais (populacionais e no mercado local e regional de trabalho), bem como a contribuição para o acirramento de desigualdades socioespaciais e os processos de reestruturação urbana e regional decorrentes. Para tanto, valeu-se de pesquisa tanto quantitativa como qualitativa, a partir de dados primários, secundários e de campo. Conclui-se que o tradicional papel de Chapecó, associado às funções de intermediação das atividades agroindustriais, ainda se mantém. Todavia, a diversificação do terciário, a entrada recente de agentes econômicos externos e a chegada de uma instituição de ensino superior federal podem sugerir que novos papéis se descortinam, de modo a refuncionalizar, em parte, a cidade na rede urbana regional. Persistem, todavia, os desafios quanto ao enfrentamento das desigualdades sociais e regionais e dos impactos ambientais engendrados no processo de (re)estruturação urbana e regional.

Palavras-chave: Cidade Média; Reestruturação Econômica; Reestruturação Urbana e Regional; Desigualdade Socioespacial; Chapecó.

\section{Summary}

This article presents an analysis about Chapecó, a city in the western region of Santa Catarina, taken from the interpretation of productive transformations, driven both by new and traditional economic agents, and its social implications, concerning changes in population and in the local and regional labor market, as well as the contribution for the intensification of socio and spatial inequalities and processes of urban and regional restructuring resulting from it. Therefore, both quantitative and qualitative research was conducted, considering primary, secondary and field data base. We conclude that the traditional role of Chapecó, associated to the agribusiness activities intermediation functions, still holds. However, the tertiary sector diversification, the recent arrival of external economic agents and the establishment of a federal university may suggest that new roles are being revealed, partly re-functionalizing the city in the regional urban network. There still remain, however, the challenges facing social and regional inequalities as well as the environmental impacts engendered in the process of urban and regional (re) structuring.

Geo UERJ - Ano 15, no. 24, v. 1, $1^{\circ}$ semestre de 2013 p. 312-338

ISSN: 1415-7543 E-ISSN: 1981-9021

http://www.e-publicacoes.uerj.br/index.php/geouerj 
Keywords: Intermediate City; Economic Restructuring, Urban and Regional Restructuring, Socio and Spatial Inequality; Chapecó.

\section{Introdução}

Atrelado ao fenômeno relativamente recente da urbanização brasileira, o crescimento não só populacional, mas econômico e de influência das cidades médias ou intermedias brasileiras têm sido objeto de debates. Mesmo que a investigação acerca desse tema tenha surgido já há algumas décadas, ainda há um campo vasto de reflexões a serem formuladas, uma vez que há escassez de estudos mais abrangentes, ao mesmo tempo que a diversidade de contextos regionais e locais, bem como as características e as estruturas espaciais, socioeconômicas e urbanas peculiares dessas cidades constituam um grande desafio analítico.

Com o intuito de contribuir com essa discussão, este artigo apresenta uma análise sobre Chapecó, na região oeste catarinense, tomada a partir da interpretação das transformações produtivas, impulsionadas por novos ou tradicionais agentes econômicos, e suas implicações sociais (populacionais e no mercado local e regional de trabalho), bem como a contribuição para o acirramento de desigualdades socioespaciais e os processos de reestruturação urbana e regional decorrentes. Reúne a síntese de diversos estudos acerca da cidade em questão, associados às investigações sobre as cidades médias, desenvolvidas no âmbito de uma pesquisa em rede que estuda esta temática.

Coloca-se, então, como objetivo deste trabalho, a caracterização de Chapecó como cidade média, realizada por meio de diversas variáveis de estudo segundo eixos representativos de atividades econômicas e o padrão de localização das mesmas, de modo a enfocar sua forma de estruturação e as dinâmicas e funções de intermediação que ela desempenha. Parte-se para a hipótese que o urbano e a cidade passam, atualmente, por um momento singular no tocante à reafirmação ou à redefinição de seu papel de intermediação na região em que se insere.

Quanto à metodologia e as informações consideradas na investigação, esta pesquisa foi desenvolvida a partir dos processos que compõem a proposta metodológica da Rede Internacional de Pesquisadores sobre Cidades Médias (ReCiMe), presentes em Spósito

Geo UERJ - Ano 15, nº 24 , v. $1,1^{\circ}$ semestre de 2013 p. 312-338

ISSN: 1415-7543 E-ISSN: 1981-9021

http://www.e-publicacoes.uerj.br/index.php/geouerj 
et al (2007). Nela são elencados quatro eixos para identificar os processos e fenômenos próprios das cidades médias, a saber: i) Ramos de atividades econômicas representativas da atuação dos novos agentes econômicos; ii) Dinâmica populacional e mercado de trabalho; iii) Equipamentos e infraestruturas e iv) Condições de moradia.

Em cada um destes eixos foram estipuladas variáveis e questões orientadoras. Para tanto, valeu-se de pesquisa tanto quantitativa como qualitativa, a partir de dados primários, secundários e de campo. Os resultados aqui reunidos foram desenvolvidos no âmbito de diversas pesquisas realizadas entre 2008 e 2012, por essa autora, bem como outros pesquisadores pertencentes ao grupo de pesquisa ${ }^{1}$ associado à ReCiMe.

No Oeste Catarinense, Chapecó é um município localizado a aproximadamente $588 \mathrm{Km}$ de distância em relação à capital do estado de Santa Catarina, Florianópolis. É delimitado ao sul pelo estado do Rio grande do Sul, ao norte pelo estado do Paraná, a oeste pela Argentina e ao leste pela região do Planalto Catarinense. Para o IBGE (2010), esta região é denominada de Mesorregião Oeste Catarinense, constituída por 118 municípios, representando $40 \%$ dos municípios catarinenses, ocupando um território de $25.300 \mathrm{~km}^{2}$, o que representa $26 \%$ da área total catarinense, com uma população de 1,6 milhões de habitantes, com aproximadamente $37 \%$ da população residente no meio rural e $63 \%$ da população residente no meio urbano. Com população aproximada de 183.500 habitantes em 2010 (IBGE, 2010), Chapecó é a maior cidade da região Oeste Catarinense e exerce influência regional, não só sobre o oeste e meio oeste de Santa Catarina (SC), mas também o norte do Rio Grande do Sul (RS), e o sudoeste do Paraná (PR), como mostra a figura abaixo. Chapecó sedia a Associação dos Municípios do Oeste de Santa Catarina (AMOSC).

Desde a sua criação em 1917, a população de Chapecó vem continuamente aumentando. Muito embora os índices de crescimento demográfico venham decrescendo nas últimas décadas, ainda assim permanecem acima da média estadual de $2 \%$ ao ano, com mais de $90 \%$ de sua população residindo na área urbana. A cidade é a sexta mais populosa no estado, depois de Joinville, Florianópolis, Blumenau, São José e Criciúma, nessa ordem. Sua importância para a rede urbana regional é caracterizada tanto pela persistência de seu papel como polo regional, assim como a progressiva estruturação como cidade

Geo UERJ - Ano 15, nº. 24, v. 1, $1^{\circ}$ semestre de 2013 p. 312-338

ISSN: 1415-7543 E-ISSN: 1981-9021

http://www.e-publicacoes.uerj.br/index.php/geouerj 
média, que exerce funções de intermediação nas relações de caráter tanto horizontal como vertical, como poderá ser averiguado nesse breve relato.

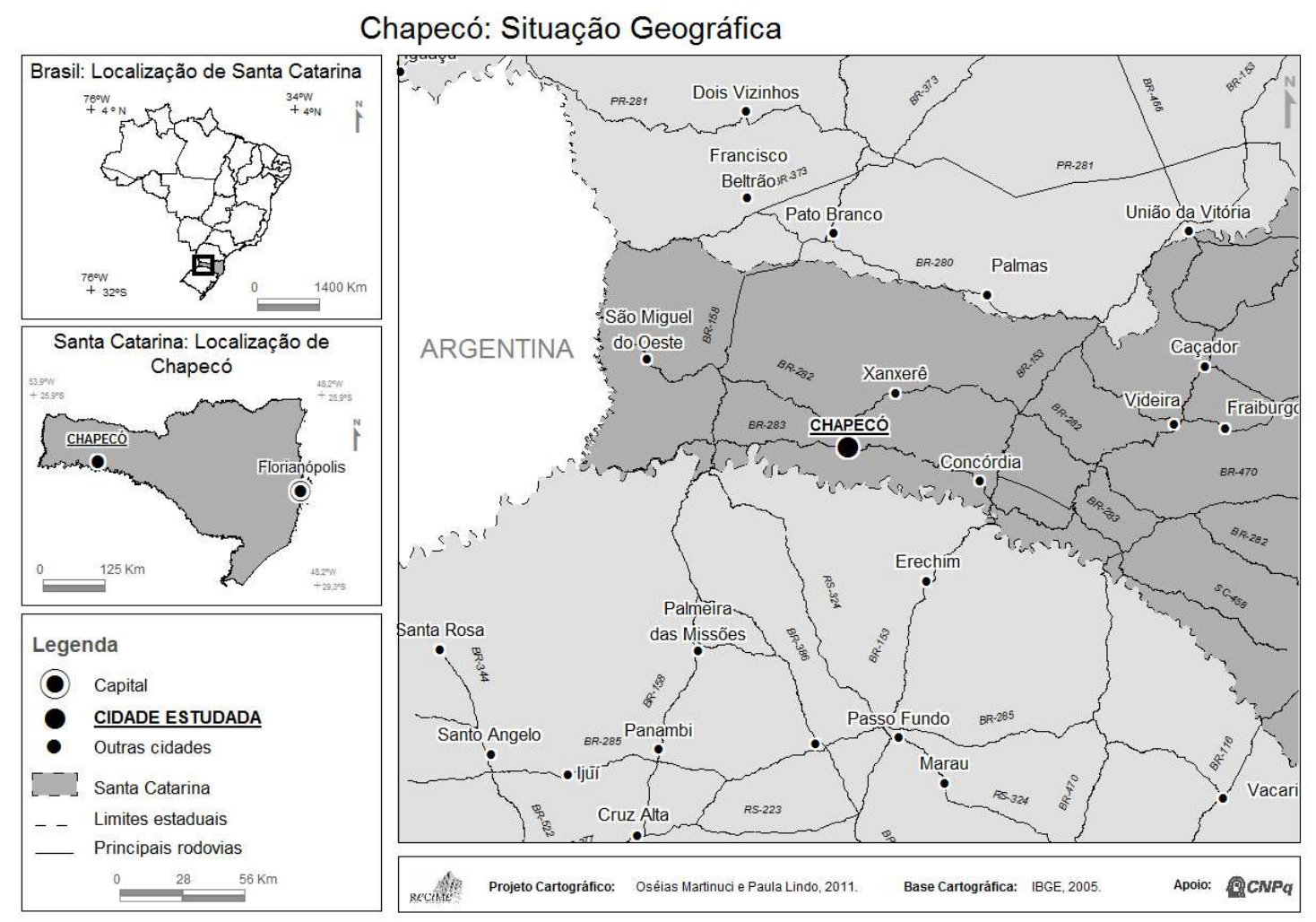

Figura 1: Chapecó. Situação Geográfica

O estudo aqui apresentado estrutura-se em quatro partes além essa introdução e as referências no final, a saber: i) primeiramente, o processo de formação urbana e regional é retratado, para fins de contextualização; ii) na segunda parte, a dinâmica de Chapecó é discutida, segundo a presença do setor agroindustrial e do terciário; iii) depois, a estruturação a cidade é retratada com base no exposto anteriormente e nos processos referentes à (re)produção das desigualdades socioespaciais; e iv) por fim, uma síntese acerca da caracterização da cidade é apresentada, segundo as funções que têm exercido, bem como algumas possibilidades de transformação futuras, tanto no aspecto urbano e regional como na mudança dos agentes atuantes na cidade. 


\section{Formação urbana e regional: breve panorama}

O processo de estruturação urbana de Chapecó está pautado na formação socioeconômica da região em que se insere. As atividades econômicas presentes na região, desde o século XVIII, foram a pecuária e a erva-mate, as quais foram motivadoras, dentre outros aspectos, de diversos conflitos que se sucederam, envolvendo países e estados, até o início do século XX, quando o munícipio de Chapecó foi criado. Em 25 de agosto de 1917, Chapecó contava com uma extensão territorial que abrangia desde o meio oeste de Santa Catarina até a fronteira oeste. Houve também inúmeras disputas quanto à decisão acerca da localização da sede municipal, que mudou diversas vezes, até que em 1922 houve a fixação definitiva em Passo dos Índios, atual área urbana de Chapecó.

A ocupação territorial desta região no século XX ocorreu por meio da colonização empresarial, de modo que tais empresas ganharam a concessão para a exploração e comercialização das terras, que em sua maioria foram vendidas aos migrantes de descendentes europeus oriundos das colônias gaúchas, a partir de 1920. A atividade madeireira esteve associada a esse processo, mediante incentivo governamental, também devido ao interesse de assegurar a posse das terras, além da geração dos ganhos econômicos. Essa forma de colonização aos poucos consolidou o povoamento do oeste catarinense, marcada por inúmeros percalços caracterizados pela tênue conexão da região ao resto do estado, pela precariedade e a escassez de infraestrutura e a falta de articulação aos mercados de modo geral. Assim, a partir da cultura de subsistência, um novo perfil socioeconômico começou então a se delinear baseado na cultura da produção de excedentes, mesmo que de modo artesanal, levando a organização inicial do núcleo urbano da cidade. Todavia, os antigos habitantes - indígenas e caboclos expropriados de suas terras e seu modo de vida, foram completamente excluídos do novo sistema econômico e fundiário que gradativamente se instalava (RENK, 1997).

Este isolamento dos centros de comercialização e a necessidade crescente dos migrantes obrigou-os a transformar seus produtos, também em busca de maior durabilidade, o que fomentou a ciclo da agroindustrialização mais adiante. A diversidade produtiva das propriedades, associada à distância e à dificuldade do transporte de grãos produzidos na

Geo UERJ - Ano 15, nº 24 , v. $1,1^{\circ}$ semestre de 2013 p. 312-338

ISSN: 1415-7543 E-ISSN: 1981-9021

http://www.e-publicacoes.uerj.br/index.php/geouerj 
região serviram de base para a dinâmica do sistema agroalimentar, já que os grãos produzidos serviam de alimento para a criação de pequenos animais, como galinhas e porcos, nas propriedades (BAVARESCO, 2005). A intermediação entre o produtor e o consumidor era exercida pelo comerciante que comprava os excedentes e os vendia nos estabelecimentos comerciais, agregando crescente influência econômica, de modo que foi a partir dela que foi gerado o capital investido na estruturação das agroindústrias. Fica evidente a interdependência entre o rural e o urbano, que pautam as relações de Chapecó e região até os dias atuais e cada vez mais fortemente.

Ao longo das décadas seguintes, houve o gradativo incremento das atividades industriais e da diversificação do comércio, impulsionando a consolidação do núcleo urbano e modificando a paisagem da cidade. Entre 1950 e 1960, embora a economia da madeira ainda fosse significativa, a suinocultura começava a despontar como atividade econômica viável que se adaptava às condições naturais e fundiárias existentes, respondendo de modo promissor à crise do pós Segunda-Guerra Mundial. O fomento à produção de matéria-prima pela produção dos excedentes contribuiu para a instalação dos primeiros frigoríficos para abate na região, como a Sadia, a Perdigão, a Chapecó Industrial e a Cooperativa Central Oeste Catarinense, visando o mercado de São Paulo e do Rio de Janeiro.

Já na década de 1960, houve as primeiras experiências de integralização do produtor rural, que mais tarde marcaria o processo de reestruturação da agroindústria com vistas à expansão de mercado, o que provocou impactos urbanos e regionais pela exclusão de muitos produtores rurais que não se adequaram à modernização do processo produtivo. A partir da década de 1960, as transformações urbanas começaram a tomar maior vulto, expressas pela melhor estruturação, com a instalação de equipamentos urbanos e instituições públicas, reforçando o papel regional da cidade, inclusive pelo considerável incremento trazido por obras viárias que atenuaram o isolamento de Chapecó e região.

O avanço da agroindustrialização nestas décadas ocorreu, em parte, também pelo incentivo financeiro do Estado, na época tomado pelos militares, além de outros fatores favoráveis como as condicionantes naturais, a pequena propriedade diversificada, a base da agricultura familiar e a cultura do trabalho e da acumulação imbuída no migrante. Outro fator determinante foi a implementação do denominado modelo de integração ${ }^{2}$,

Geo UERJ - Ano 15, nº. 24, v. 1, $1^{\circ}$ semestre de 2013 p. 312-338

ISSN: 1415-7543 E-ISSN: 1981-9021

http://www.e-publicacoes.uerj.br/index.php/geouerj 
que foi a forma encontrada para a manutenção da fragmentação dos agricultores em suas unidades produtivas, simultaneamente à sua "integração" a uma cadeia de produção necessária à nova fase de desenvolvimento do capital. Através dele, padrões de produção puderam ser preestabelecidos pela empresa, com a vantagem de manter o produtor sob o seu controle econômico e também ideológico, criando uma relação de dependência. Uma característica marcante da agroindústria, que a diferencia das demais empresas, é que nela é possível estabelecer um acirrado controle sobre outro produtor privado, no caso o agricultor, ditando regras de acordo com a necessidade de obtenção de matéria-prima no ritmo e tempo que a empresa determina (ALBA, 2002, pg. 31)

Entre as décadas de 1970 e 1980, e associado ao crescimento e à consolidação dos frigoríficos, houve também o considerável crescimento populacional de Chapecó, de 49.865 habitantes para 83.765 habitantes, respectivamente, sendo que a população urbana nesse período quase triplicou. Como ocorreu com o processo de urbanização brasileiro, foi nesse período que houve a inversão quanto ao local de moradia dos habitantes, da área rural para a urbana. Em 1970, 59\% dos moradores estavam no campo, ao passo que em 1980, essa porcentagem baixou para 34\%. Desde então, a população urbana só tem crescido, chegando a mais de $90 \%$, recentemente, como mostra a tabela abaixo. Todavia, isso de modo algum significa que o rural perdeu sua importância, já que Chapecó se revela justamente na interação dialética entre o urbano e o rural. O urbano só é urbano pela presença do rural diretamente interligado a ele, tal como se percebe ao longo desse estudo.

Tabela 1: Chapecó. Evolução da população de Chapecó e a variação percentual entre a população urbana e rural do período. 1940 a 2010

\begin{tabular}{c|c|c|c|c|c}
\hline Ano & Urbano & Var. \% & Rural & Var. \% & Total \\
\hline 1940 & 4.128 & $9,31 \%$ & 40.199 & $90,69 \%$ & 44.327 \\
\hline 1950 & 9.736 & $10,08 \%$ & 86.868 & $89,92 \%$ & 96.604 \\
\hline 1960 & 10.939 & $21 \%$ & 41.150 & $79 \%$ & 52.089 \\
\hline 1970 & 20.275 & $41,08 \%$ & 29.590 & $59 \%$ & 49.865 \\
\hline 1980 & 55.269 & $66 \%$ & 28.499 & $34 \%$ & 83.765 \\
\hline 1991 & 96.751 & $79 \%$ & 26.299 & $21 \%$ & 123.050 \\
\hline 1996 & 113.988 & $87 \%$ & 17.026 & $13 \%$ & 131.014 \\
\hline 1997 & 118.548 & $87,50 \%$ & 16.823 & $12,50 \%$ & 135.371 \\
\hline 1998 & 123.060 & $88 \%$ & 16.818 & $12 \%$ & 139.878 \\
\hline 1999 & 127.821 & $88,44 \%$ & 16.715 & $11,56 \%$ & 144.536 \\
\hline $2000 *$ & 134.592 & $91,57 \%$ & 12.375 & $8,43 \%$ & 146.967 \\
\hline 2006 & 160.855 & $93 \%$ & 12.107 & $7 \%$ & 172.962 \\
\hline
\end{tabular}

Geo UERJ - Ano 15, nº 24 , v. $1,1^{\circ}$ semestre de 2013 p. 312-338

ISSN: 1415-7543 E-ISSN: 1981-9021

http://www.e-publicacoes.uerj.br/index.php/geouerj 


\begin{tabular}{|c|c|c|c|c|c|}
\hline 2010 & 168.131 & $91,61 \%$ & 15.402 & $8,39 \%$ & 183.533 \\
\hline
\end{tabular}

De meados da década de 1980 à década seguinte, começaram também a surgir os impactos do crescimento da cadeia da agroindústria, que progressivamente se verticalizava, bem como as implicações da globalização e das políticas econômicas mundiais dominantes. Se por um lado, a agroindústria baseada na região, buscava se inserir no mercado internacionalizado, por outro, as atividades produtivas sofreram duramente pela perda de competitividade, gerando impactos sociais e ambientais nas escalas urbana e regional, provocados pela concentração e intensidade dessas mesmas dinâmicas produtivas (VIEIRA; CUNHA, 2002).

O crescimento populacional, causado pela busca por emprego e o êxodo das áreas rurais fruto dos processos de modernização da agroindústria, não ocorreu de forma assistida, em termos de provimento de políticas públicas sociais. As consequências do abrupto adensamento do espaço da cidade começaram a surgir, uma vez que o município não possuía condições para viabilizar e prover a cidade na mesma rapidez com que o seu núcleo urbano se consolidava, além do fato que, nesta época, não era preocupação corrente dos poderes públicos o enfrentamento da exclusão social. Desta forma, a desigualdade socioespacial já se fazia evidente na paisagem da cidade, com a formação de bairros operários sem infraestrutura, assentamentos precários e o despejo de populações excluídas em guetos que carregam até hoje o estigma da exclusão. Prova disso, é que entre as décadas de 1970 e 1990 tem-se o período mais intenso de surgimento de novas áreas irregulares, chegando ao percentual de 77,3\% das áreas existentes até 2011, o que revela a falta de efetividade das políticas públicas habitacionais durante este período.

Quanto aos danos para a qualidade de vida da população, associados ao descaso com o meio ambiente na cidade, citam-se os impactos causados pela urbanização deficitária e a atuação indiscriminada de empresas, que promoveram a contaminação de mananciais através de produtos químicos, a poluição atmosférica, a falta de infraestrutura, de saneamento básico, de habitação, carência/deficiência no fornecimento de energia

Geo UERJ - Ano 15, no. 24, v. 1, $1^{\circ}$ semestre de 2013 p. 312-338

ISSN: 1415-7543 E-ISSN: 1981-9021

http://www.e-publicacoes.uerj.br/index.php/geouerj 
elétrica, transporte coletivo deficitário, entre tantos outros fatores que remontam e traduzem parte do cenário da periferia de Chapecó.

No âmbito regional, o avanço do processo produtivo trouxe consigo, além da seleção/exclusão de produtores da cadeia produtiva, a concentração e o aumento de dejetos de suínos, que configura uma ameaça ambiental, pois quando é manejado de forma inadequada acarreta sérios problemas ambientais, gerando danos à saúde pública, sobretudo pela contaminação de águas superficiais. Assim, os custos sociais e ecológicos, que não são internalizados pela agroindústria, ao longo do processo produtivo, permanecem como passivos externos para natureza e a sociedade (ANSCHAU, 2011).

Entretanto, é interessante ressaltar que grande parte dos agricultores que se mantiveram no campo, mas foram excluídos pela seletividade da suinocultura, tem encontrado na bovinocultura de leite sua principal atividade econômica. Na escala regional, é possível afirmar que a bovinocultura de leite vem se destacando, na última década, na medida em que aproveita recursos que ainda estavam ociosos nas propriedades rurais, aliando mãode-obra familiar com alimentação à base de pasto. Porém, apesar do aumento experimentado, a bovinocultura também está passando por um processo de seletividade da atividade, com a ampliação das exigências aos produtores. Assim, há indícios concretos que está em curso o mesmo processo de exclusão que têm caracterizado a suinocultura e a avicultura, o que pode gerar, num futuro próximo, obstáculos à expansão da atividade, bem como inúmeros impactos sociais que se refletirão no território, seja no campo ou na cidade, reconfigurando a estrutura urbana e regional, já que no tocante à intrínseca relação entre o rural e o urbano, nenhum se sobrepõe ao outro, pois novas relações são continuamente (re)construídas.

Contudo, é inegável que a agroindústria ainda perfaz a base da economia de Chapecó e região, de modo que essa atividade possui papel importante na estruturação da cidade, sobretudo por sua vinculação com o mercado nacional e internacional. Os avanços que houveram de novas atividades também são consequências disso. Dessas pode-se citar o setor terciário, que vai se consolidando e consequentemente mudando o cenário socioeconômico da cidade, de modo que será comentado mais adiante. Todo este processo tem interferido fortemente na taxa de crescimento nos últimos anos e na

Geo UERJ - Ano 15, nº 24 , v. $1,1^{\circ}$ semestre de 2013 p. 312-338

ISSN: 1415-7543 E-ISSN: 1981-9021

http://www.e-publicacoes.uerj.br/index.php/geouerj 
estruturação do núcleo urbano da cidade, consolidando novos hábitos que se evidenciam no processo de transformação do local.

A fim de complementar a discussão feita até o momento, segue breve consideração acerca dos papéis desempenhados por Chapecó na região, a partir do estudo das redes urbanas e suas relações de influência.

\section{Dinâmica de Chapecó: cidade média e polo regional}

Para se pensar o papel da cidade, faz-se necessário relacionar a sua inserção regional nos processos de intermediação de troca de fluxos (bens, consumidores, serviços, informações, etc.), que perpassa a observação dialógica entre o urbano e o rural e, também, as articulações transescalares que ocorrem entre o local e o global. Também há que se ter em conta diversos elementos e relações, as quais refletem especificidades que influenciam o município e a região, características que marcam a configuração da rede urbana e regional, as áreas de influência das cidades, bem como as estruturas sociais, organizacionais e econômicas existentes, que influem nos processos de territorialização, em constante transformação.

Então, para se pensar o seu papel de intermediação faz-se pertinente considerar o processo de conformação territorial e da rede urbana catarinense. As características do relevo e da influência sociocultural na estruturação fundiária, as divisões políticoadministrativas e de regionalização, bem como das condições produtivas e de infraestrutura contribuíram para a formação, no estado, de uma rede urbana composta por cidades de pequeno e médio porte (SIEBERT, 2001), de caráter multipolarizado (ANJOS, 2007), agrupadas em regiões que se organizam, dentre esses e outros fatores, sob a lógica de ramos dinamizadores da economia no estado. O oeste Catarinense, dentro desse contexto, caracteriza-se pela marcada presença da atividade agroindustrial focada na produção de alimentos (suinocultura e avicultura e, mais recentemente, a bovinocultura de leite) e suas cadeias correlatas.

Geo UERJ - Ano 15, no. 24, v. 1, $1^{\circ}$ semestre de 2013 p. $312-338$

ISSN: 1415-7543 E-ISSN: 1981-9021

http://www.e-publicacoes.uerj.br/index.php/geouerj 
A evolução do papel de Chapecó na rede urbana regional e nacional pode ser apreendida a partir dos estudos do IBGE sobre as relações de rede, hierarquia e região de influência que as cidades exercem umas sobre outras. Uma breve análise da inserção de Chapecó nos estudos realizados (1966, 1978, 1993 e 2008) aponta para a crescente influência da cidade no oeste catarinense, configurando como a mais influente capital regional (nível B), desde o meio oeste do estado até a fronteira, ligando-se à rede urbana de Curitiba e Porto Alegre (IBGE, 2008).

A rede urbana no oeste catarinense resulta principalmente dos processos de reestruturação produtiva da agropecuária, dos investimentos de capitais locais e estatais para o crescimento da agroindústria, o processo de (des)concentração de unidades de produção e suas cadeias correlatas, bem como da inserção destas atividades produtivas nas dinâmicas econômicas internacionais, incorporando padrões de produção e consumo globalizados. Associada a esse processo, a cadeia produtiva atrelada à agroindústria também se diversificou e se instalou em Chapecó e na região de modo representativo.

\begin{tabular}{|c|c|c|}
\hline $\begin{array}{c}\text { Faixa exportada } \\
\text { (US\$ FOB) }\end{array}$ & $\begin{array}{l}\text { Número de } \\
\text { empresas }\end{array}$ & Empresas \\
\hline Até US\$ 1 milhão & 25 & $\begin{array}{l}\text { - APC do Brasil Ltda } \\
\text { - Apti Alimentos Ltda } \\
\text { - Armv - Representações Comerciais Ltda } \\
\text { - Atividades Montagens Industriais Ltda* } \\
\text { - Bioter Proteção Ambiental Ltda } \\
\text { - Bumerangue Brasil Industrial Ltda } \\
\text { - Chapecó Indústria e Comércio de Fibras Ltda } \\
\text { - Clean Tec Serviços de Limpeza Ltda } \\
\text { - CNA - Comércio e Indústria de Produtos Automotivos Ltda } \\
\text { - Coriarte Tintas Ltda. ME } \\
\text { - Cristalflex Indústria de Espumas e Colchões Ltda } \\
\text { - Edege Equipamentos Agropecuários Ltda* } \\
\text { - Frigo Industrial Ltda* } \\
\text { - Globoaves São Paulo Agroavícola Ltda* } \\
\text { - High Tech Equipamentos Industriais Ltda* } \\
\text { - Laboratórios Pfizer Ltda* } \\
\text { - Nord Equipamentos Industriais AS* } \\
\text { - Nutract Agroindustrial Ltda* } \\
\text { - Pri ME Comercial Importadora e Exportadora Ltda } \\
\text { - RM Indústria e Comércio Ltda* } \\
\text { - Sganderla Comercial Importadora Ltda. - EPP } \\
\text { - Tronic Indústria de Materiais Esportivos Ltda } \\
\text { - Usitécnica Industrial Ltda } \\
\text { - Vetanco do Brasil Importação e Exportação Ltda } \\
\text { - Viclau - Comercial, Importadora e Exportadora Ltda. - ME }\end{array}$ \\
\hline $\begin{array}{l}\text { Entre US\$ } 1 \text { e } 10 \\
\text { milhões }\end{array}$ & 2 & $\begin{array}{l}\text { - Rotoline Equipamentos Industriais Ltda } \\
\text { - Semil - Equipamentos Industriais Ltda* }\end{array}$ \\
\hline
\end{tabular}

Geo UERJ - Ano 15, nº 24 , v. $1,1^{\circ}$ semestre de 2013 p. 312-338

ISSN: 1415-7543 E-ISSN: 1981-9021

http://www.e-publicacoes.uerj.br/index.php/geouerj 
*Empresas ligadas ao setor agroindustrial

Fonte: Santa Catarina em Números (2010, p. 36-37)

Organizada por Rosa Salete Alba.

Quadro 1: Chapecó. Empresas exportadoras de Chapecó, segundo as faixas de valores exportados (US\$ FOB), até UF\$ 10 milhões. 2008.

Com base no documento do Sebrae, Santa Catarina em números (2010), pode-se analisar as empresas exportadoras do município classificadas segundo o volume de suas exportações até US\$ 10 milhões, como mostra o quadro 1. Constata-se que, se por um lado há o crescimento e a diversificação de atividades em Chapecó, aquelas ligadas à rede agroindustriais ainda são numerosas, demonstrando a relevância da cadeia para a economia local e regional. Os dados apontam que $37 \%$ das empresas exportadoras possuem correlação com o setor, tal como: indústrias de máquinas e equipamentos para frigoríficos, suinocultura, avicultura e bovinocultura de leite ou laboratórios de medicamentos para esses setores.

Tabela 2: Chapecó. Número de empregos gerados em Chapecó, segundo o porte e participação relativa. 2008.

\begin{tabular}{|c|c|c|c|c|c|c|c|}
\hline \multicolumn{8}{|c|}{$\begin{array}{l}\text { Seção de Atividade Econômica, segundo classificação CNAE - versão } 2.0 \\
2008\end{array}$} \\
\hline & Total & ME & $\mathbf{P E}$ & MDE & GE & $\begin{array}{l}\text { Partic. } \\
(\%)\end{array}$ & $\begin{array}{l}\text { Evol. } \\
2006 / 08\end{array}$ \\
\hline $\begin{array}{l}\text { Agricultura, pecuária, } \\
\text { produção florestal, pesca e } \\
\text { aqüicultura }\end{array}$ & 952 & 367 & 366 & 98 & 121 & $1,5 \%$ & $11,3 \%$ \\
\hline Indústrias extrativas & 15 & 15 & - & - & - & $0,0 \%$ & $25,0 \%$ \\
\hline $\begin{array}{l}\text { Indústrias de } \\
\text { transformação }\end{array}$ & 20.792 & 2.449 & 3.274 & 2.683 & 12.386 & $33,0 \%$ & $25,0 \%$ \\
\hline Eletricidade e gás & 213 & 23 & - & 190 & - & $0,3 \%$ & $0,0 \%$ \\
\hline $\begin{array}{l}\text { Água, esgoto, atividades de } \\
\text { gestão de resíduos e } \\
\text { descontaminação }\end{array}$ & 314 & 65 & 20 & 229 & - & $0,5 \%$ & $88,0 \%$ \\
\hline Construção & 4.870 & 1.682 & 2.597 & 591 & - & $7,7 \%$ & $113,4 \%$ \\
\hline $\begin{array}{l}\text { Comércio; reparação de } \\
\text { veículos automotores e } \\
\text { motocicletas }\end{array}$ & 15.245 & 5.618 & 6.068 & 2.037 & 1.522 & $24,2 \%$ & $25,8 \%$ \\
\hline $\begin{array}{l}\text { Transporte, armazenagem e } \\
\text { correio }\end{array}$ & 3.934 & 676 & 1.153 & 519 & 1.586 & $6,2 \%$ & $18,9 \%$ \\
\hline $\begin{array}{l}\text { Seção I - Alojamento e } \\
\text { alimentação }\end{array}$ & 1.349 & 677 & 611 & 61 & - & $2,1 \%$ & $17,7 \%$ \\
\hline Informação e comunicação & 677 & 179 & 498 & - & - & $1,1 \%$ & $14,4 \%$ \\
\hline $\begin{array}{l}\text { Atividades financeiras, de } \\
\text { seguros e serviços } \\
\text { relacionados }\end{array}$ & 1.159 & 173 & 536 & 64 & 386 & $1,8 \%$ & $-16,3 \%$ \\
\hline
\end{tabular}

Geo UERJ - Ano 15, nº 24 , v. $1,1^{\circ}$ semestre de 2013 p. 312-338

ISSN: 1415-7543 E-ISSN: 1981-9021

http://www.e-publicacoes.uerj.br/index.php/geouerj 


\begin{tabular}{llllllll}
\hline Atividades imobiliárias & 217 & 43 & 174 & - & - & $0,3 \%$ & $26,9 \%$ \\
\hline $\begin{array}{l}\text { Atividades profissionais, } \\
\text { científicas e técnicas }\end{array}$ & 911 & 451 & 460 & - & - & $1,4 \%$ & $31,6 \%$ \\
\hline $\begin{array}{l}\text { Atividades administrativas } \\
\text { e serviços complementares }\end{array}$ & 1.702 & 454 & 420 & 141 & 687 & $2,7 \%$ & $20,8 \%$ \\
\hline $\begin{array}{l}\text { Administração pública, } \\
\text { defesa e seguridade social }\end{array}$ & 4.148 & 3 & - & 111 & 4.034 & $6,6 \%$ & $18,4 \%$ \\
\hline $\begin{array}{l}\text { Educação } \\
\text { Saúde humana e serviços } \\
\text { sociais }\end{array}$ & 1.970 & 179 & 500 & 108 & 1.183 & $3,1 \%$ & $16,1 \%$ \\
\hline $\begin{array}{l}\text { Artes, cultura, esporte e } \\
\text { recreação }\end{array}$ & 189 & 118 & 71 & - & - & $0,3 \%$ & $17,4 \%$ \\
\hline $\begin{array}{l}\text { Outras atividades de } \\
\text { serviços }\end{array}$ & 2.575 & 583 & 375 & 290 & 1.327 & $4,1 \%$ & $27,9 \%$ \\
\hline Serviços domésticos & 11 & 11 & - & - & - & $0,0 \%$ & $0,0 \%$ \\
\hline $\begin{array}{l}\text { Organismos internacionais } \\
\text { e outras instituições } \\
\text { extraterritoriais }\end{array}$ & - & - & - & - & - & $0,0 \%$ & $0,0 \%$ \\
\hline Total & $\mathbf{6 3 . 0 2 4}$ & $\mathbf{1 4 . 2 8 9}$ & $\mathbf{1 7 . 2 6 5}$ & $\mathbf{7 . 1 2 2}$ & $\mathbf{2 4 . 3 4 8}$ & $\mathbf{1 0 0 , 0 \%}$ & $\mathbf{2 6 , 4 \%}$ \\
\hline
\end{tabular}

Fonte: Santa Catarina em Números (2010, p. 36).

Organizado por Rosa Salete Alba, 2011.

Uma relação que ranqueou e premiou as grandes empresas, empresas de pequeno porte e micro empresas na área da indústria e do comércio de destaque, em 2010, denominada "Troféu Desbravador", , aponta que das quinze grandes empresas industriais, onze delas referem-se às próprias agroindústrias ou aquelas relacionadas á elas. Igualmente, nota-se a listagem de muitas dessas empresas com o setor agroindustrial, reforçando que boa parte da economia de Chapecó ainda tem uma grande relação com esse setor. Da mesma forma, é importante registrar que das quinze maiores empresas comerciais, cinco delas atuam no fornecimento de produtos para agropecuária, sendo que três delas são empresas de grande porte que têm suas filiais instaladas em Chapecó e atuam em escala nacional e internacional.

No caso das empresas de comércio e prestação de serviços, do total de 12.463, 9.658 estão ligadas a esse setor, refletindo a tendência geral já comentada acerca do crescimento do setor terciário da economia nas últimas décadas, assim como sua complexificação que se reflete na dinâmica urbana e regional, bem como na geração de empregos, conforme tabela 02 , que evidencia evolução em todos os setores, com exceção das atividades financeiras e de seguros, que possivelmente concentram-se nos centros de maior influência.

Geo UERJ - Ano 15, no. 24, v. 1, $1^{\circ}$ semestre de 2013 p. $312-338$

ISSN: 1415-7543 E-ISSN: 1981-9021

http://www.e-publicacoes.uerj.br/index.php/geouerj 
Quanto ao número de empregos gerados no setor terciário, vale destacar que dentre os empregos vinculados aos diferentes setores, do total de 63.024 empregos, 36.395 são referentes às diferentes atividades ligadas ao serviço e comércio, representando 57,74\% do total, sendo que a indústria é responsável por 25.677 empregos (40,74\%) e a agricultura por 952 empregos (1,52\%), como mostra a tabela 2. Disso, pode-se afirmar que a importância do setor do agronegócio/agroindústrias ainda é de significativa importância. Porém, como observado no estudo de sua região de influência abordado anteriormente, Chapecó vem assumindo novas e importantes funções, que serão caracterizadas ao longo desta análise.

Outro aspecto que demonstra o papel que o setor agropecuário possui para o município e a região é a realização do turismo de negócios e das feiras voltadas para a cadeira agropecuária. Dentre elas pode-se citar a Exposição Feira Agropecuária e Industrial (EFAPI), que acontece de dois em dois anos, e é uma feira diversificada voltada principalmente para o setor agropecuário, com considerável volume de negócios, mas também para outras atividades de comércio e serviços. Há também a Mercoagro e a Mercoláctea, além de outras feiras voltadas ao setor de transporte que é a Logistique e a Mercomóveis, relacionada ao mercado imobiliário. A presença do aeroporto reforça a dinâmica desses eventos e do papel da cidade como importante nó de conexão logística em escala regional.

Além da atividade agroindustrial, como já dito, o crescimento populacional e o relativo isolamento regional estimulou também o crescimento, a diversificação e a complexificação do terciário nesta rede urbana, visto as análises que apontam para o considerável grau de centralidade nas atividades de comércio, sob o aspecto da diversidade e serviço e comércio (FUJITA, ALBA, MATIELLO, 2009). A constituição desse terciário orienta-se, tanto às demandas de consumo consumptivo, de uma população com relativo poder aquisitivo, a qual se encontra distante de centros urbanos maiores, quanto ao consumo produtivo das redes de comércio e serviço especializadas associadas à atividade agroindustrial.

Quanto à origem do capital nesse setor, nota-se ainda certo predomínio de capitais de origem local, mas que recentemente dá indícios da entrada de agentes econômicos externos, com capital nacional e internacional. As lojas e os supermercados por muito

Geo UERJ - Ano 15, nº. 24, v. 1, $1^{\circ}$ semestre de 2013 p. 312-338

ISSN: 1415-7543 E-ISSN: 1981-9021

http://www.e-publicacoes.uerj.br/index.php/geouerj 
tempo foram dominados por capitais locais e regionais, com alguma participação de redes nacionais na última década. Interessante notar que a entrada da Havan, em 2007, estabeleceu um marco divisório na dinâmica do comércio da cidade e suas relações trabalhistas, pois essa empresa exigiu mudanças na legislação municipal e tem conseguido permanecer aberta conforme seu padrão de funcionamento de horário estendido, produzindo mudanças significativas no comportamento das demais lojas estabelecidas na cidade, que por força da concorrência também passaram a adotar os mesmos padrões A mudança do horário de atendimento do comércio tem sido um dos debates polêmicos nos últimos anos em Chapecó, pois as novas redes induzem a uma nova cultura de consumo na cidade e região, antes inexistente, modificando a rotina dos empregados no comércio, fato que repercute tanto no ambiente social como familiar dos mesmos (HENN, SORBAZO, ALBA, 2009).

No tocante à entrada de capitais estrangeiros, muito recentemente, em 2011, houve a implantação do primeiro shopping center da região, filiada à marca Pátio, com a presença de redes e filiais de comércio, tais como lojas âncora, cadeias de fast food, dentre outros, cuja localização foi estratégica, a fim de captar a clientela local e regional, no prolongamento do eixo central que concentra o setor terciário, mas ainda com grande potencial de ampliação, valorização e incorporação imobiliária do entorno. No setor dos supermercados, que sempre operou sob a predominância de capitais locais, também demonstra o surgimento de novos agentes, com a entrada a rede Wallmart, que em 2009 implantou o Maxxi Atacado e há a previsão e o início das obras de um supermercado da rede Big Shop. O mesmo pode se afirmar quanto à rede hoteleira, com o anúncio da implantação de um hotel da rede Ibis, em uma nova frente de expansão imobiliária de alto padrão e localizada em um entroncamento importante de eixos viários.

A presença destas redes internacionais em Chapecó reflete o recentíssimo momento que a cidade presencia com a entrada de capitais externos, tal como tem se verificado no atual contexto da urbanização nacional nas cidades do porte como o de Chapecó, devido ao potencial de expansão de mercado local e regional a médio e longo prazos que essas cidades apresentam.

Geo UERJ - Ano 15, nº. 24, v. 1, $1^{\circ}$ semestre de 2013 p. 312-338

ISSN: 1415-7543 E-ISSN: 1981-9021

http://www.e-publicacoes.uerj.br/index.php/geouerj 
As redes bancárias e financeiras existentes em Chapecó, por sua vez, exercem influência regional no oeste catarinense, consolidando-se como nó articulador de cidades e de novas funções urbanas em escala regional. Há na cidade a presença de agências de diferentes redes bancárias, tanto na modalidade atacado como as de varejo, bem como as superintendências regionais e os postos de serviços bancários. No setor do atacado há o atendimento específico para as empresas e produtores associados à cadeia da agroindústria.

Segundo dados do Caderno de Informações Socioeconômicas do Município de Chapecó (2009), verificou-se uma evolução em quase todas as principais operações bancárias desenvolvidas nos anos de 2007 e 2008, se comparadas com 2006. Destaca-se também a evolução de créditos destinados ao setor agropecuário e aos financiamentos destinados às agroindústrias. Em 2007, foi observado um crescimento de $24 \%$ de financiamentos destinados a custeio e investimentos agropecuários; $38 \%$ para crédito agropecuário, e um espantoso aumento de 196\% de financiamentos destinados às agroindústrias, superando a média nacional, conforme a mesma fonte de dados. Em 2008, houve crescimento de $41 \%$ nos primeiros meses do ano, e uma retração de $8 \%$ nos meses seguintes, inferior a 2007. Os financiamentos agropecuários e agroindustriais representam 50\% dessas operações, em Chapecó. Em 2008, os financiamentos agropecuários sofreram retração de quase 9\%, enquanto aqueles agroindustriais apresentaram elevação de 23,26\%; os depósitos desse setor passaram de 20 milhões em 2007, para 24,6 milhões em 2008.

Com relação ao setor de serviços de saúde especializado, nota-se que ao longo das últimas décadas, Chapecó passou a ser referência microrregional para diversos tipos de serviços na área da saúde, seja pela exclusividade ou pelo grau de especialidade. É notável que a demanda existente supera a oferta desses serviços, sobretudo no âmbito público, o que tem ampliado as fatias de mercado no caso privado, observado pelo aumento significativo de clínicas, consultórios particulares e lojas especializadas, nos últimos anos. Associada à essa dinâmica, tem havido a especialização funcional de áreas da cidade que concentram esses serviços, assim como a ampliação de oferta de cursos (técnicos, graduação e pósgraduação) na área da saúde, por parte dos estabelecimentos de ensino público e privado.

Geo UERJ - Ano 15, no. 24, v. 1, $1^{\circ}$ semestre de 2013 p. $312-338$

ISSN: 1415-7543 E-ISSN: 1981-9021

http://www.e-publicacoes.uerj.br/index.php/geouerj 
No ensino superior, a última década também registrou o aparecimento de inúmeras instituições privadas de ensino associadas às redes nacionais, com predominância de cursos oferecidos na modalidade à distância. Esse panorama tende a se ampliar, pois em 2010 houve a implantação da sede da primeira universidade federal da região, a Universidade Federal da Fronteira Sul (UFFS), que já demonstra impactos sociais e econômicos sobre a realidade do município, sobretudo na ampliação da oferta imobiliária e do aumento do preço do solo urbano nas imediações do futuro campus definitivo da universidade.

O setor imobiliário é outro ramo que apresentou significativo crescimento, nos últimos anos. Foi verificado no período de 2007 e 2008 um aumento de 57,5\% de financiamentos imobiliários, mantendo o ritmo de crescimento e atingindo $46 \% \mathrm{em}$ 2008. (CADERNOS DE INFORMAÇÕES SOCIOECONÔMICAS DO MUNICÍPIO DE CHAPECÓ, 2009). Todavia, nesse setor, é ainda predominante a presença de empreendedores locais representados pelas maiores incorporadoras imobiliárias da cidade. Com a oferta de financiamentos e a alta do mercado, tem havido a proliferação de empresas menores alimentadas por capitais locais ou regionais, vinculados ao produtor associado à agroindústria. Como poderá ser observado a seguir, a dinâmica econômica existente, a ausência de políticas públicas eficazes e o predomínio da atuação privada têm produzido diversos impactos expressos na ampliação das desigualdades socioespaciais.

\section{Estrutura de Chapecó: do crescimento à desigualdade}

Uma avaliação comparativa entre os dados dos Censos Demográficos do IBGE (2010), dos anos de 2000 e 2010, mostrados anteriormente, demonstra que houve nessa década um crescimento populacional de 24,90\%. Dos 183.533 habitantes, em 2010, quase a totalidade vive em área urbana, perfazendo uma taxa de urbanização de 91,61\%.

Geo UERJ - Ano 15, nº 24 , v. $1,1^{\circ}$ semestre de 2013 p. 312-338

ISSN: 1415-7543 E-ISSN: 1981-9021

http://www.e-publicacoes.uerj.br/index.php/geouerj 


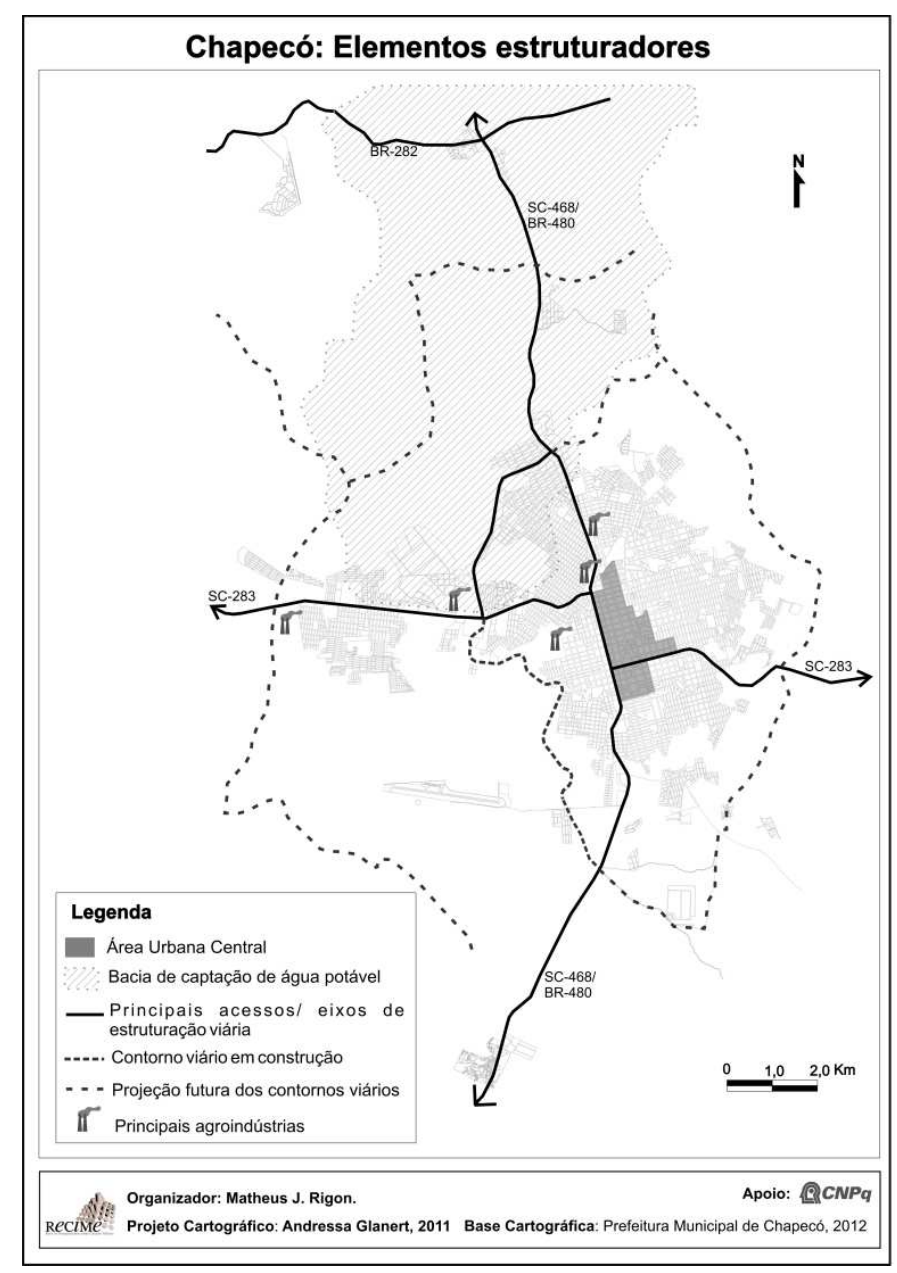

Figura 2: Chapecó. Elementos estruturadores da cidade.

Essa população se distribui em 31 bairros (PMC, 2012), os quais foram se consolidando a partir da área central e dos principais eixos viários que promovem acesso à cidade, orientados segundo os sentidos norte-sul e leste-oeste, como pode ser observado na figura 02. O eixo norte-sul é articulado: a norte, pelas rodovias SC 468/SC 480; e a sul, pela SC 468/SC480. O eixo leste-oeste é estruturado pela rodovia SC 283. Essas rodovias constituem um relevante entroncamento de conexão com o Rio Grande do Sul, bem como com a fronteira e o litoral catarinense.

A partir disso, pode-se estabelecer uma subdivisão do conjunto da cidade em duas grandes porções, perceptíveis na figura 2, a saber: i) uma área agregada pela região central, composta pela maior parte dos bairros e ordenada a partir do eixo norte-sul e do centro e, ii) outra concentração na porção oeste, formada pelo Efapi, maior bairro da

Geo UERJ - Ano 15, nº. 24, v. 1, $1^{\circ}$ semestre de 2013 p. 312-338

ISSN: 1415-7543 E-ISSN: 1981-9021

http://www.e-publicacoes.uerj.br/index.php/geouerj 
cidade que é acessado pelo eixo viário da Avenida Senador Atílio Fontana, que por sua vez se conecta à rodovia SC 283.

Estas áreas são fisicamente separadas por alguns fatores de limitação hidrográfica e de relevo. Há, a noroeste, a área da bacia de captação para abastecimento de água, conhecida como Lajeado São José e, a sudoeste, uma região de relevo acidentado, como observado na figura acima. Todavia, a construção de contornos viários tem promovido a conexão do setor oeste ao eixo norte-sul, bem como a indução de urbanização nessas áreas. Á noroeste há o contorno da Av. Leopoldo Sander, construída na década de 1970, que promove a ligação norte-oeste e passa pela área da bacia hidrográfica e, atualmente, em fase de conclusão, há o contorno viário interno oeste, fazendo a ligação oeste-sul na área de difícil ocupação. Como pode-se constatar nas figuras, as principais agroindústrias instaladas na cidade localizam-se ao longo desses eixos.

Segundo dados disponibilizados pela Prefeitura de Chapecó (2012), o maior bairro da cidade é o Efapi, formado a partir da população trabalhadora da agroindústria e de estudantes, como já mencionado, cuja área ocupa 12,18 \% da área urbana e abrigava, em 2010, 26.543 habitantes, a maior população por bairro na cidade, praticamente o dobro da população do centro, que com 13.060 habitantes é o segundo bairro mais populoso (CHAPECÓ, 2012).

Com relação à distribuição geral do uso do solo, também é possível explicá-la a partir dos eixos viários estruturadores, os quais aglutinam em geral os usos não residenciais.

O acesso ao município pelo trevo norte, situado no entroncamento da BR $282 \mathrm{com}$ a SC 468/SC 480, é denominado Acesso Plínio Arlindo de Nês, o qual realiza a conexão desse trevo até o perímetro urbano de Chapecó, atuando como um dos mais importantes meios para entrada e saída da cidade. Embora seja atualmente constatada a precariedade do mesmo, devido às más condições de infraestrutura - sobretudo, da pavimentação destaca-se o início das obras de duplicação e a construção de alguns elevados neste trecho visando à melhoria da mobilidade e a segurança dos veículos que trafegam diariamente, tratando-se de uma via de intenso fluxo, tanto de cargas quanto de passageiros.

Devido à sua localização estratégica, este acesso abriga, em sua extensão, uma concentração de empresas e indústrias que foram se instalando ao longo dos anos, as

Geo UERJ - Ano $15, n^{\circ} .24$, v. $1,1^{\circ}$ semestre de 2013 p. 312-338

ISSN: 1415-7543 E-ISSN: 1981-9021

http://www.e-publicacoes.uerj.br/index.php/geouerj 
quais se beneficiam desta localização, visto que este importante eixo de conexão com a BR 282 e a SC 468/SC480 facilita o escoamento da produção, bem como a entrada de insumos, produtos, serviços e consumidores. Por esse mesmo motivo, na conexão deste eixo norte com principais avenidas centrais da cidade, localizou-se o primeiro shopping center de Chapecó e região de influência, como mencionado anteriormente.

O uso do solo ao longo do Acesso Plínio Arlindo de Nês engloba diversos ramos de atividades. Dentre estas, destacam-se as empresas distribuidoras de produtos como: alimentos, bebidas, autopeças, móveis e eletrodomésticos. Além destes usos, há a consolidação de empresas concessionárias de veículos leves e pesados, abrigando também serviços de assistência técnica para o setor automotivo, bem como empresas que atuam no setor de logística e de transporte de cargas em geral. Esse caráter também é encontrado no contorno da Av. Leopoldo Sander, já citado.

A partir dos investimentos de novas indústrias que optam por implantarem-se nas proximidades deste eixo viário, observa-se também a conformação de bairros mais afastados do centro da cidade. Desta forma, há três assentamentos habitacionais dispostos ao logo do Acesso Plínio Arlindo de Nês, que são: o Bairro Belvedere, o Bairro Vila Rica e o Bairro Trevo. A precária qualidade de infraestrutura e de moradia existente nos mesmos, a longa distância em relação ao centro da cidade, acarretando dificuldades de mobilidade para as populações residentes, e as atuais obras de duplicação propiciam conflitos pelo uso residencial e empresarial/industrial. Muito embora a taxa de renda por domicílio não seja baixa, tal qual no bairro Trevo.

Outro fator de conflito ocorre por conta dos acessos á essas atividades localizarem-se sobre a área da bacia de captação, como dito anteriormente, a qual está gravada pelo Plano Diretor de Desenvolvimento Territorial de Chapecó (PDDTC, 2004) como MBCAP (Macroárea da Bacia de Captação de Água Potável). Segundo o plano, esta área deve ter sua integridade ambiental assegurada, bem como seu potencial hídrico preservado, o que não está acontecendo devido ao tipo de urbanização em curso e também por alterações na legislação que têm sido mais permissivas à urbanização, como a lei complementar que autorizou a revisão do plano diretor no ano de 2007.

A área central, por sua vez, estruturada pelas avenidas também em sentido norte-sul, concentram as atividades do setor terciário no município e apresentam crescente

Geo UERJ - Ano 15, no. 24, v. 1, $1^{\circ}$ semestre de 2013 p. 312-338

ISSN: 1415-7543 E-ISSN: 1981-9021

http://www.e-publicacoes.uerj.br/index.php/geouerj 
verticalização. Na continuação desse eixo, o acesso sul, realizado através da SC 468/SC480, destina-se a ocupação de caráter industrial e atualmente apresenta uma concentração ainda baixa, tanto de indústrias como de empresas. Porém, vem se desenvolvendo continuamente, por meio de duas áreas localizadas em sua proximidade, que são: O Distrito Industrial Quedas do Palmital e o Distrito Industrial Flávio Baldissera. A localização do aeroporto e a implantação do contorno viário interno oeste, já mencionado, constituem fatores indutores de urbanização.

Os acessos no sentido leste-oeste, realizados a partir da SC 283, possuem um caráter um pouco diferente dos citados anteriormente. No sentido Oeste, a rodovia compreende a Avenida Senador Atílio Fontana, a qual se constitui como via estruturadora do bairro Efapi, com características de um subcentro de Chapecó, o qual possui forte caráter terciário, com usos associados ao comércio e serviços, como redes bancárias, lojas de vestuário, de móveis e eletrodomésticos, de materiais de construção, de produtos alimentícios, alguma prestação de serviços públicos, informática, dentre outros.

Outro aspecto relevante é a localização das principais agroindústrias instaladas na cidade, como a Sadia e a Aurora, dispostas ao longo deste trecho na porção oeste. A constituição dos bairros lindeiros às agroindústrias está diretamente ligada à implantação das mesmas no tecido urbano da cidade, pois tem recebido ao longo do tempo o contingente de operários que trabalham na indústria.

No sentido leste, as Ruas Uruguai e Euclides Prade dão continuidade à SC 283 e também têm papel de via estruturadora, porém, a consolidação de usos ligados ao setor terciário é menor neste trecho.

A partir destes eixos estruturadores, os bairros são distribuídos e possuem característica predominantemente monofuncional residencial unifamiliar e multifamiliar, não existindo verticalização muito evidente. Porém, a partir de algumas vias de caráter estrutural, aonde são previstos maiores gabaritos e diversificação de usos, a verticalização está gradativamente surgindo.

Observa-se, que os bairros mais elitizados, com maior rendimento mensal por responsável pelo domicílio, são o centro, a leste o Maria Goretti e o Presidente Médice, e a oeste o Jardim Itália. Esses dois últimos receberam aporte de investimentos infraestruturais advindos do governo federal, por meio do Programa Comunidade

Geo UERJ - Ano 15, nº. 24, v. 1, $1^{\circ}$ semestre de 2013 p. 312-338

ISSN: 1415-7543 E-ISSN: 1981-9021

http://www.e-publicacoes.uerj.br/index.php/geouerj 
Urbana para Recuperação Acelerada (CURA), nos anos de 1970, e continuam recebendo equipamentos e investimentos urbanos de considerável vulto, como por exemplo, o Centro de Eventos Municipal e a Arena Condá, o estádio da Associação Chapecoense de Futebol.

Os bairros que apresentam maior carência infraestrutural e que abrigam a população mais carente, com menor rendimento mensal por responsável pelo domicílio estão localizados em áreas periféricas, com algum tipo de restrição ambiental ou aquelas historicamente constituídas como áreas de segregação, como é o caso do bairro São Pedro. Percebe-se, assim, a persistência de um padrão de periferização, que ocorre a partir da área central e dos principais eixos viários de acesso à cidade, como ilustra a figura 03.

A compreensão da evolução urbana da cidade de Chapecó, de seus elementos estruturadores, da morfotipologia, dos padrões de localização de infraestrutura, equipamentos e de atividades por setor econômico, bem como da distribuição das condições de moradia demonstra que a estruturação da cidade se dá segundo a conformação de centralidades, constituídas a partir das infraestruturas viárias que dão acesso à cidade e concentram as atividades do setor industrial, agroindustrial e do terciário já descrito anteriormente. 


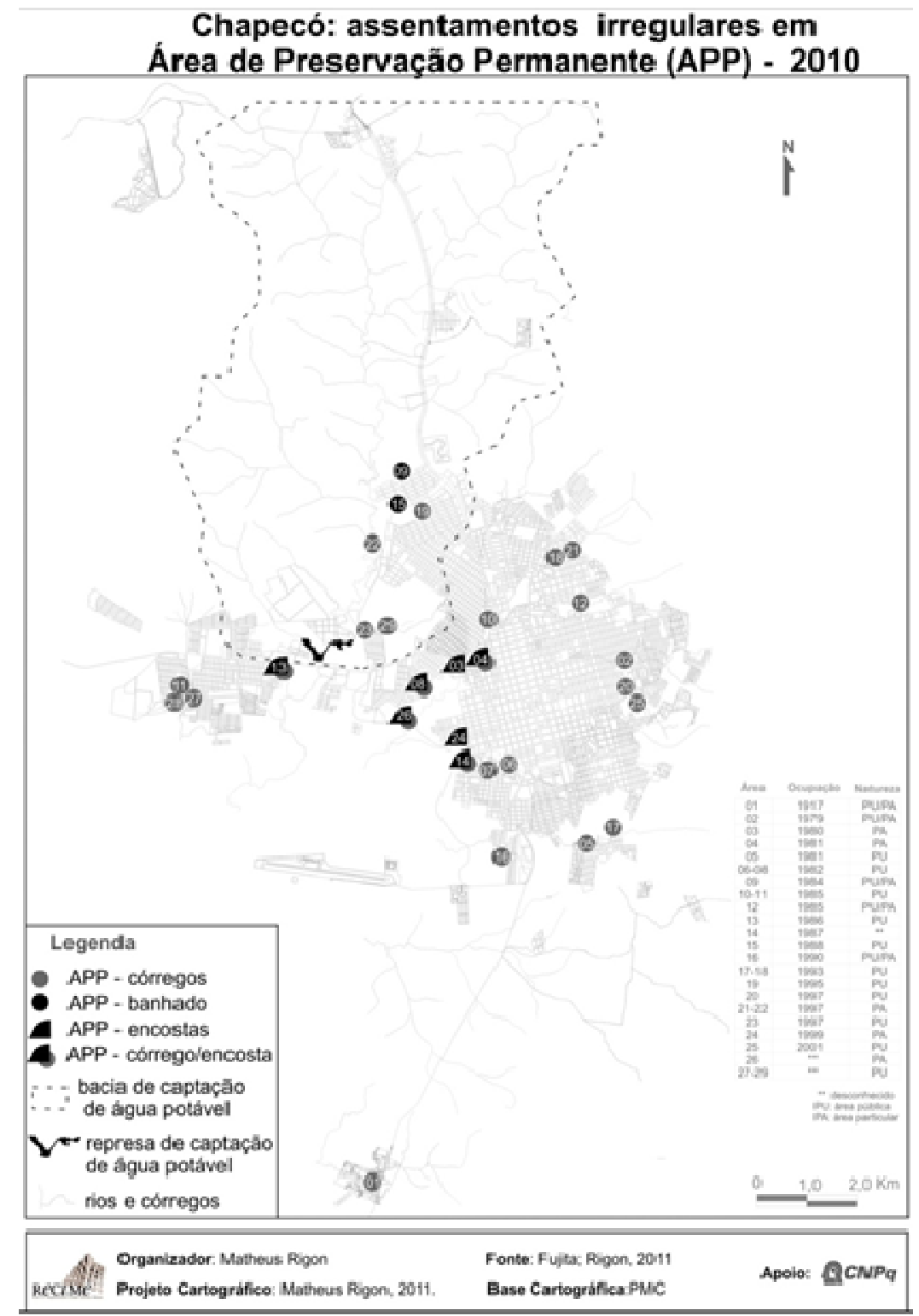

Figura 3: Chapecó. Assentamentos irregulares em APP. 2010. Elaborado por Matheus Rigon, 2011.

A partir destas estruturas viárias distribuem-se os locais de moradia, de modo concêntrico, segundo categorias sociais e econômicas, estando os locais mais elitizados próximos ao centro. Persiste, assim, o padrão de periferização dos assentamentos precários e informais, com escassez de investimentos públicos de melhoria nesses locais, e o espraiamento descontínuo do tecido urbano, permeado por vazios destinados à especulação imobiliária, acirrando as desigualdades sociais e espaciais.

Geo UERJ - Ano 15, no. 24, v. 1, $1^{\circ}$ semestre de 2013 p. $312-338$

ISSN: 1415-7543 E-ISSN: 1981-9021

http://www.e-publicacoes.uerj.br/index.php/geouerj 
Com relação à dinâmica imobiliária e da construção civil é notável o grande crescimento desse setor, ainda com predomínio de empresas de origem e capital local como já dito. O mercado de terras tem estipulado preços de imóveis comparados aos de capitais, mesmo que o padrão das edificações oferecido, principalmente para as camadas populares, seja bastante pobre. Dados da Prefeitura Municipal (2012) mostram que o número de liberações de habite-se praticamente dobrou de 2010 para 2011 e metade dos loteamentos aprovados, em 2011, são no bairro Efapi, aonde serão as instalações permanentes do campus da UFFS.

Além disso, os impactos ambientais provocados pelo processo de urbanização, das atividades industriais, do terciário e de moradia, são significativos, sobretudo na bacia hidrográfica de abastecimento de água da cidade (FACCO, 2011). A situação se agrava com a pouca regulação do uso do solo, por parte do poder público, em especial nas recentes administrações, que tem progressivamente alterado os parâmetros e índices construtivos fixados no ordenamento territorial do plano diretor, em suas revisões, em favor dos interesses de empreendedores do setor imobiliário, principalmente com relação à desafetação e diminuição de parâmetros em áreas de interesse e preservação ambiental.

\section{Considerações Finais}

Com base no exposto, conclui-se que o tradicional papel de Chapecó, associado às funções de intermediação das atividades agroindustriais, ainda se mantém. Chapecó enquanto cidade média, e ainda como polo, tem protagonizado uma dinâmica importante no contexto regional e nacional, atraindo atividades econômicas antes presentes apenas em grandes centros. A diversificação do terciário, a entrada recente de agentes econômicos externos e a chegada de uma instituição de ensino superior federal podem sugerir que novos papéis se descortinam, de modo a refuncionalizar em parte a cidade na rede urbana regional.

Os papéis de intermediação que a cidade exerce na rede urbana estão intimamente atrelados à região, entre verticalidades e horizontalidades, que remetem à relação

Geo UERJ - Ano 15, no. 24, v. 1, $1^{\circ}$ semestre de 2013 p. 312-338

ISSN: 1415-7543 E-ISSN: 1981-9021

http://www.e-publicacoes.uerj.br/index.php/geouerj 
dialética entre o urbano e o rural. Na perspectiva das horizontalidades, configura-se como polo do setor terciário na região. Até pouco tempo atrás, esse setor era dominado por capitais locais, porém, muito recentemente tem havido a entrada de capitais nacionais e internacionais na rede de comércio e serviços, ligada às lojas e supermercados, com uma possível tendência no incremento dos serviços de saúde e de educação. No caso das verticalidades, Chapecó insere-se na dinâmica do agronegócio, dando suporte à atividade agroindustrial voltada ao mercado internacional, a qual está calcada na produção de alimentos, mais especificamente na suinocultura, na avicultura e, mais recentemente, na bovinocultura de leite.

Todavia, o desenvolvimento e a consolidação deste papel vêm acompanhados da incapacidade das políticas urbanas em atender as necessidades da população de baixa renda, muito embora existam investimentos públicos em grandes projetos urbanos que funcionam como marketing para atrair novos capitais. $\mathrm{O}$ atendimento da demanda por habitação e da estrutura a ela relacionada fica condicionado ao interesse privado, que sofre pouca regulação por parte das próprias instituições públicas que a fomentam. Persistem, assim, os desafios quanto ao enfrentamento das desigualdades sociais e regionais e dos impactos sociais e ambientais engendrados no processo de (re)estruturação urbana e regional.

\footnotetext{
${ }^{1}$ Este artigo reúne reflexões contidas no relatório final sobre a caracterização da cidade de Chapecó formulado para a Rede de Pesquisadores sobre Cidades Médias, sob reponsabilidade dessa autora, Camila Fujita, além de Rosa Salete Alba, Alexandre Maurício Matiello, Ana Laura Vianna Villela, Cleusa Teresinha Anschau e Cristina Otsuschi, aos quais reconhecemos muitas das reflexões aqui contidas. Também agradecemos a colaboração dos diversos bolsistas de iniciação científica que auxiliaram na coleta de dados e na composição das diversas pesquisas que compuseram o relatório mencionado.
}

2 A cadeia produtiva de suínos e aves do Oeste Catarinense tem sido fomentada pelo modelo de integração, onde o produtor rural faz parte do processo produtivo. De um lado, há a agroindústria que fornece assistência técnica e é responsável pela absorção da matéria-prima e, de outro há o produtor rural, que garante a produção e a manutenção dessa matéria-prima nos padrões de qualidade exigidos pela empresa. Cerca de $82 \%$ da produção de carnes, matéria prima com padrões fitossanitários internacionais, vem do sistema integrado (ACCS, 2011).

${ }^{3}$ O Troféu Desbravador tem como objetivo destacar as empresas (industriais, comerciais, estatais e prestadoras de serviços) e produtores rurais do município com maior incidência de ICMS. Toma como base o valor adicionado, apurado na declaração de informações do ICMS e no movimento econômico DIME, e na declaração anual do simples nacional - DASN. As fontes para a classificação das empresas prestadoras de serviços na área de incidência do ISS e os produtores agropecuários são, respectivamente, a secretaria municipal da Fazenda e Administração e a secretaria municipal da Agricultura de Chapecó.

Geo UERJ - Ano 15, nº. 24, v. 1, $1^{\circ}$ semestre de 2013 p. 312-338

ISSN: 1415-7543 E-ISSN: 1981-9021

http://www.e-publicacoes.uerj.br/index.php/geouerj 


\section{Referências}

ASSOCIAÇÃO CATARINENSE DE CRIADORES DE SUÍNOS - ACCS. Relatório anual 2010. Disponível em: http// www.accs.org.br . Acesso em fev/2011.

ALBA, Rosa Salete. Espaço Urbano: os agentes da produção em Chapecó. Chapecó: Argos, 2002. 184 p.

ANJOS, Francisco Antônio dos. O sistema urbano multi-polarizado de Santa Catarina. In: Maria Encarnação Beltrão Spósito (Org.). Cidades Médias: espaços em transição. 1 ed., v. 1. São Paulo: Expressão Popular, 2007. 632 p. p. 413-438..

ANSCHAU, Cleusa Terezinha. Redes cooperativas da bovinocultura de leite e o desenvolvimento do Oeste Catarinense. Dissertação (Mestrado em Ciências Ambientais), Programa de Pós-graduação em Ciências Ambientais, Universidade Comunitária da Região de Chapecó, 2011.

BAVARESCO, Paulo Ricardo. Ciclos econômicos regionais: modernização e empobrecimento no Extremo Oeste catarinense. Chapecó: Argos, 2005. 219 p.

CADERNOS DE INFORMAÇÕES SOCIOECONÔMICAS DO MUNICÍPIO DE CHAPECÓ. Chapecó, 2009 - ano 10 - No. 19, 20 e 21. $3^{\text {a }}$. Edição Especial.

FACCO, Janete. Os conflitos ambientais no processo de urbanização da bacia hidrográfica de abastecimento de água de Chapecó-SC. Dissertação (Mestrado. em Ciências Ambientais), Programa de Pós-graduação em Ciências Ambientais, Universidade Comunitária da Região de Chapecó, 2011.

Geo UERJ - Ano 15, nº 24 , v. $1,1^{\circ}$ semestre de 2013 p. $312-338$ ISSN: 1415-7543 E-ISSN: 1981-9021 http://www.e-publicacoes.uerj.br/index.php/geouerj 
FUJITA, Camila; MATIELLO, Alexandre Maurício; ALBA, Rosa Salete. Rede de polo e micropolos regionais no oeste catarinense. Revista Redes, Santa Cruz do Sul, v. 14, n. 2, p. 53-79, mai./ago, Disponível em: www.unisc.br/seer/index.php/redes. Acesso em: 06 dez. 2009.

HENN, Cristiane Gretzler; SOBARZO, Oscar; ALBA, Rosa Salete. Agentes econômicos e novas dinâmicas em cidades médias: Análise das redes de lojas de departamento em Chapecó - SC. In: ENCONTRO NACIONAL DA ANPEGE, 28 de setembro a 02 de outubro de 2009, Curitiba PR. Anais..., Curitiba: ANPEGE, 2009.

INSTITUTO BRASILEIRO DE GEOGRAFIA E ESTATÍSTICA - IBGE. Censo Demográfico. Disponível em: http://www.ibge.gov.br. Acesso em: out. 2010.

INSTITUTO BRASILEIRO DE GEOGRAFIA E ESTATÍSTICA - IBGE. Regiões de Influência das Cidades 2007. Rio de Janeiro: IBGE, 2008. Disponível em: http://www.ibge.gov.br. Acesso em: 06 mai. 2009.

PDDTC. Plano Diretor de Desenvolvimento Territorial de Chapecó - PDDTC. Chapecó: PMC, 2004.

PREFEITURA MUNICIPAL DE CHAPECÓ - PMC. Chapecó em dados. Disponível em: http://www.chapeco.sc.gov.br/. Acesso em: 21 abr 2012.

RENK, Arlene. A luta da erva: um ofício étnico no Oeste catarinense. Chapecó: Grifos 1997. $226 \mathrm{p}$.

SIEBERT, Cláudia. Panorama do planejamento regional em Santa Catarina: da centralização à construção da solidariedade regional. In: ___ (org.) Desenvolvimento Regional em Santa Catarina: reflexões, tendências e perspectiva. Blumenau: Edifurb, 2001. pg. 139-166.

Geo UERJ - Ano $15, n^{\circ} .24$, v. 1, $1^{\circ}$ semestre de 2013 p. $312-338$ ISSN: 1415-7543 E-ISSN: 1981-9021 http://www.e-publicacoes.uerj.br/index.php/geouerj 


\section{SERVIÇO BRASILEIRO DE APOIO ÀS MICRO E PEQUENAS EMPRESAS -}

SEBRAE. Santa Catarina em números: Chapecó. Florianópolis: Sebrae/SC. Disponível em: www.sebrae-sc.com.br/scemnumero/arquivo/Chapeco.pdf . Acesso em: out., 2010.

SPOSITO, Maria Encarnação Beatriz, et all. O estudo das cidades médias brasileiras: uma proposta metodológica. In: (org.); Cidades médias: espaços em transição. 1. Ed. São Paulo: Expressão Popular, 2007. 632 p.

VIEIRA, Paulo Freire; CUNHA, Idauto José. Repensando o Desenvolvimento Catarinense. In: VIEIRA, Paulo Freire (org.). A Pequena produção e o modelo catarinense de desenvolvimento. Florianópolis: APED, 2002. pg. 289-310.

Artigo recebido para publicação em maio de 2013.

Artigo aceito para publicação em maio de 2013. 